\title{
Prestress Force Identification for Externally Prestressed Concrete Beam Based on Frequency Equation and Measured Frequencies
}

\author{
Luning Shi, Haoxiang He, and Weiming Yan \\ Beijing Laboratory of Earthquake Engineering and Structure Retrofit, Beijing University of Technology, Beijing 100124, China \\ Correspondence should be addressed to Haoxiang He; hhx7856@163.com
}

Received 29 March 2014; Accepted 14 May 2014; Published 29 May 2014

Academic Editor: Qingsong Xu

Copyright (c) 2014 Luning Shi et al. This is an open access article distributed under the Creative Commons Attribution License, which permits unrestricted use, distribution, and reproduction in any medium, provided the original work is properly cited.

\begin{abstract}
A prestress force identification method for externally prestressed concrete uniform beam based on the frequency equation and the measured frequencies is developed. For the purpose of the prestress force identification accuracy, we first look for the appropriate method to solve the free vibration equation of externally prestressed concrete beam and then combine the measured frequencies with frequency equation to identify the prestress force. To obtain the exact solution of the free vibration equation of multispan externally prestressed concrete beam, an analytical model of externally prestressed concrete beam is set up based on the BernoulliEuler beam theory and the function relation between prestress variation and vibration displacement is built. The multispan externally prestressed concrete beam is taken as the multiple single-span beams which must meet the bending moment and rotation angle boundary conditions, the free vibration equation is solved using sublevel simultaneous method and the semi-analytical solution of the free vibration equation which considered the influence of prestress on section rigidity and beam length is obtained. Taking simply supported concrete beam and two-span concrete beam with external tendons as examples, frequency function curves are obtained with the measured frequencies into it and the prestress force can be identified using the abscissa of the crosspoint of frequency functions. Identification value of the prestress force is in good agreement with the test results. The method can accurately identify prestress force of externally prestressed concrete beam and trace the trend of effective prestress force.
\end{abstract}

\section{Introduction}

Externally prestressed concrete structure is broadly applied in the highway bridges, urban bridges, and railway bridges with the development of external prestress technology. In design and construction process of externally prestressed concrete bridge, the prestress force is often determined according to the theory formula [1]. But in the actual construction process, many factors such as relaxation of steel, shrinkage and creep of concrete, and ambient temperature can lead to the change of the prestress force and the prestress force can show obvious change when the concrete beam has the cracks or failure. Therefore, in order to effectively control the operating state and the bearing capacity of bridges, it is very important to identify the prestress force of externally prestressed concrete bridge. The existing method which has good accuracy is to install force sensors in the prestressed concrete beam to monitor the change of the prestress force. The disadvantage of this approach is that the sensor is expensive and the accuracy of the force sensor will decrease with the increase of age in services. Above all, it is necessary to find a simple and effective method to identify the prestress force. In recent years, scholars did a lot of research on identification of prestress force and obtained some results.

Lu and Law [2] presented a method for the identification of prestress force of a prestressed concrete bridge deck using the measured structural dynamic responses and the prestress force is identified using a sensitivity-based finite element model updating method in the inverse analysis. Law and $\mathrm{Lu}$ [3] also studied the time-domain response of a prestressed Euler-Bernoulli beam under external excitation based on modal superposition and the prestress force is identified in 
the time domain by a system identification approach. $\mathrm{Li}$ et al. [4] carried out numerical simulations to identify the magnitude of prestress force in a highway bridge by making use of the dynamic responses from moving vehicular loads based on dynamic response sensitivity-based finite element model updating. Law et al. [5] developed a new method of prestress identification using the wavelet-based method in which the approximation of the measured response is used to form the identification equation. Bu and Wang [6] presented a BP neural network method to identify the effective prestress for a simply supported PRC beam bridge based on modal frequencies and dynamic responses of the bridge. Abraham et al. [7] investigated the feasibility of using damage location algorithm technique for detecting loss of prestress in a prestressed concrete bridge. Kim et al. [8] studied a vibrationbased method to detect prestress loss in beam-type PSC bridges by monitoring changes in a few natural frequencies. Xuan et al. [9] evaluated the prestress loss quantitatively in the steel-strand reinforced structures by an optical fibersensor based monitoring technique. However, the prestress force and prestress loss cannot be estimated directly, simply, and accurately unless the beam has been instrumented at the time of construction. Several researchers also studied the dynamic behavior of prestressed beam with external tendons and predicted the relation between the modal frequency and the given prestress force. Miyamoto et al. [10] studied the effect of the prestressing force introduced by the external tendons on the vibration characteristics of a composite girder with the results of dynamic tests and derived the formula for calculating the natural frequency of a composite girder based on a vibration equation. Hamed and Frostig [11] presented the effect of the magnitude of the prestressing force on the natural frequencies of prestressed beams with bonded and unbonded tendons. Saiidi et al. [12, 13] reported a study on modal frequency due to the prestress force with laboratory test results. The above researchers only considered the prestressing effect on dynamic characteristics of the simply supported beam. Very few works have been presented on the effect of prestressing on the dynamic responses of a beam and identification of prestress force directly or indirectly.

The exact solution of the free vibration equation of multispan externally prestressed concrete uniform beam is obtained in this paper. An inverse problem to identify the prestress force based on the frequency equation and the measured frequencies is then presented taking the prestress force as an unknown parameter in the frequency functions. The prestress force identification method is suited to the externally prestressed concrete uniform beam. Firstly, based on Miyamoto et al's study [10], the function relation between prestress variation and vibration displacement of multispan externally prestressed concrete beam is built according to the basic principle of the force method. The multispan externally prestressed concrete beam is considered as the multiple single-span beams which must meet the bending moment and rotation angle boundary conditions. The free vibration equations of multispan externally prestressed concrete beam by using sublevel simultaneous method which can simplify the solution of dynamic equations are given and the semianalytical solution of the free vibration equations which

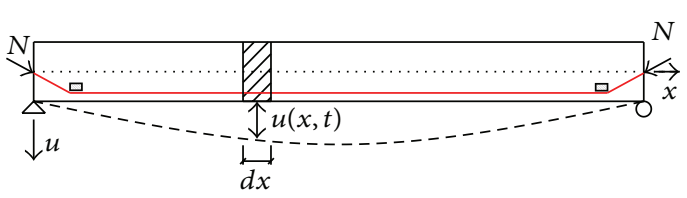

FIgURE 1: Analysis model of vibration system.

considered the influence of prestress on section rigidity and beam length is obtained. Then, frequency functions which are obtained by frequency equation are used to identify the prestress force by the appropriate method. Two dynamic tests of externally prestressed concrete beam in the laboratory are submitted to illustrate the effectiveness and robustness of the proposed method. At last, the effect of the error of the measured frequencies on identification of the prestress force is studied in the proposed method.

\section{Vibration Equation of Multispan Externally Prestressed Concrete Beam}

2.1. Vibration Equation of Externally Prestressed Simply Supported Beam. An externally prestressed simply supported beam is shown in Figure 1. It is assumed that the prestress force $N$ has no prestressing loss along the beam length and the beam bending must meet the plane section assumption. The vibration equation of this simply supported beam can be expressed as follows:

$$
\begin{aligned}
\frac{\partial^{2}}{\partial x^{2}}\left[E I \frac{\partial^{2} u(x, t)}{\partial x^{2}}\right]+N_{x} \frac{\partial^{2} u(x, t)}{\partial x^{2}}-H \frac{\partial^{2}(\Delta N)}{\partial x^{2}} \\
+m \frac{\partial^{2} u(x, t)}{\partial t^{2}}=0,
\end{aligned}
$$

where $E I$ is the flexural rigidity of the beam, $m$ is the mass of the beam per unit length, $\mu(x, t)$ is the transverse deflection, $N_{x}$ is the horizontal component of the prestress force $N, H$ is the equivalent eccentricity of the external tendons, and $\Delta N$ is the variation of the prestress force due to flexural vibration. Because eccentricity of external tendons in different positions on the beam is not the same, the equivalent eccentricity $H$ can be calculated according to the principle of equal area in the bending moment diagram.

\subsection{Vibration Equation of Multispan Externally Prestressed} Beam. A multispan externally prestressed continuous beam which has $n$ spans is shown in Figure 2 and the $i$ th span of the beam is taken as the study subject. The rotation angle and bending moment of the beam end at point $i$ are $\theta_{i, i+1}$ and $M_{i, i+1}$ and the rotation angle and bending moment of the beam end at point $i+1$ are $\theta_{i+1, i}$ and $M_{i+1, i}$, respectively. 


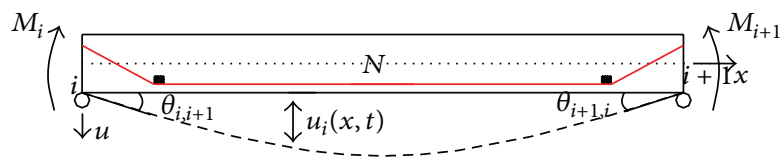

FIgURE 2: Analysis model of the $i$ th span of the beam.

According to (1), the free vibration equation of the $i$ th span of the beam can be written as follows:

$$
\begin{aligned}
\frac{\partial^{2}}{\partial x^{2}}\left[E I \frac{\partial^{2} u_{i}(x, t)}{\partial x^{2}}\right] & +N_{x i} \frac{\partial^{2} u_{i}(x, t)}{\partial x^{2}}-H_{i} \frac{\partial^{2}\left(\Delta N_{i}\right)}{\partial x^{2}} \\
& +m \frac{\partial^{2} u_{i}(x, t)}{\partial t^{2}}=0,
\end{aligned}
$$

where $\mu_{i}(x, t)$ is the transverse deflection of the $i$ th span, $H_{i}$ is the equivalent eccentricity of the external tendons of the $i$ th span, $\Delta N_{i}$ is the variation of the prestress force due to flexural vibration of the $i$ th span, and $N_{x i}$ is the horizontal component of the prestress force $\mathrm{Ni}$ of the $i$ th span.

The rotation angle and bending moment at both ends of the $i$ th span of the beam need to satisfy the following boundary conditions:

$$
\begin{array}{cc}
\theta_{i, i-1}=\theta_{i, i+1}, & M_{i, i-1}=M_{i, i+1}, \\
\theta_{i+1, i}=\theta_{i+1, i+2}, & M_{i+1, i}=M_{i+1, i+2} .
\end{array}
$$

The first and the last span of multispan externally prestressed concrete beam must meet the boundary conditions

$$
\begin{array}{ccc}
M_{1,2}=0, & \theta_{2,1}=\theta_{2,3}, & M_{2,1}=M_{2,3}, \\
M_{n+1, n}=0, & \theta_{n, n+1}=\theta_{n, n-1}, & M_{n, n+1}=M_{n, n-1} .
\end{array}
$$

Obviously, the free vibration equation of multispan externally prestressed concrete beam can be considered to be the free vibration equations of multiple single-span externally prestressed beams which must satisfy the rotation angle and bending moment boundary conditions, as shown in (3) and (4). In order to solve the vibration equations, relations between prestress variation $\Delta N$ and vibration displacement $u(x, t)$ should be defined firstly.

2.3. Relations between Prestress Variation and Vibration Displacement. Prestress force would change as the vibration displacement during the free vibration of multispan externally prestressed concrete beam, the free vibration of the beam, is considered in small deformation condition, so relations between prestress variation $\Delta N$ and vibration displacement $u(x, t)$ can approximatively be seen as a linear relationship on the geometric deformation $[10,14]$. Assume that there is a concentrated force $F$ on the midspan of the beam to get the relations between prestress variation $\Delta N$ and concentrated force $F$, then to obtain the relations between vibration displacement $u(x, t)$ and concentrated force $F$, and at last to find the relationship between prestress variation $\Delta N$ and vibration displacement $u(x, t)$ by variable replacing.
The side $\operatorname{span}(i=1, n)$ of the multispan externally prestressed concrete beam can be simplified approximately as the structure shown in Figure 3(a). Concentrated force $F$ acts on the midspan of the side span beam model, the prestress variation $\Delta N$, and bending moment on the support are identified as the unknown forces $X_{1}$ and $X_{2}$ and the basic system can be generated after removing the redundant constraints. The bending moment diagrams with the unknown forces $X_{1}=1$ and $X_{2}=1$ and concentrated force $F$ acting on the beam model are shown in Figure 3(a). The deformation compatibility equations can be written as follows:

$$
\begin{aligned}
& \delta_{11} X_{1}+\delta_{12} X_{2}+\Delta_{1 F}=0, \\
& \delta_{21} X_{1}+\delta_{22} X_{2}+\Delta_{2 F}=0,
\end{aligned}
$$

where $\delta_{i j}=\sum \int\left(\bar{M}_{i} \bar{M}_{j} / E I\right) d x+\sum \int\left(\bar{N}_{i} \bar{N}_{j} / E A\right) d x, \Delta_{i F}=$ $\sum \int\left(\bar{M}_{i} M_{F} / E I\right) d x+\sum \int\left(\bar{N}_{i} N_{F} / E A\right) d x, i=1,2, j=1,2$. Equation (5) can be rewritten as follows:

$$
\Delta N=\frac{\delta_{12} \Delta_{2 F}-\delta_{22} \Delta_{1 F}}{\delta_{11} \delta_{22}-\delta_{12} \delta_{21}} .
$$

The vertical displacement $\mu_{F}$ on the midspan of the side span beam model can be expressed as follows:

$$
\mu_{F}=\frac{7 F L^{3}}{768 E I} .
$$

Substituting (6) into (7), we can get the following:

$$
\mu_{F}=\frac{7\left(\delta_{11} \delta_{22}-\delta_{12} \delta_{21}\right) F L^{3}}{768\left(\delta_{12} \Delta_{2 F}-\delta_{22} \Delta_{1 F}\right) E I} \Delta N .
$$

When concentrated force $F$ acts on the midspan of the beam model, the vertical displacement $\mu_{F}$ can be produced at the midspan and external tendons can produce internal force which will produce the prestress variation $\Delta N$. At the same time, internal force will lead to the vertical displacement $\mu_{\Delta N}$ which has the opposite direction of the $\mu_{F}$. The vertical displacement $\mu_{\Delta N}$ can be written as follows:

$$
\mu_{\Delta N}=\frac{\delta_{22} \Delta_{1 F}-\delta_{12} \Delta_{2 F}}{\delta_{22} E I F} \Delta N .
$$

The vertical displacement $\mu$ which is caused by the concentrated force $F$ can be calculated as follows:

$$
\mu=\mu_{F}-\mu_{\Delta N} .
$$

Substituting (8) and (9) into (10), we can obtain

$$
\Delta N=\phi \mu,
$$




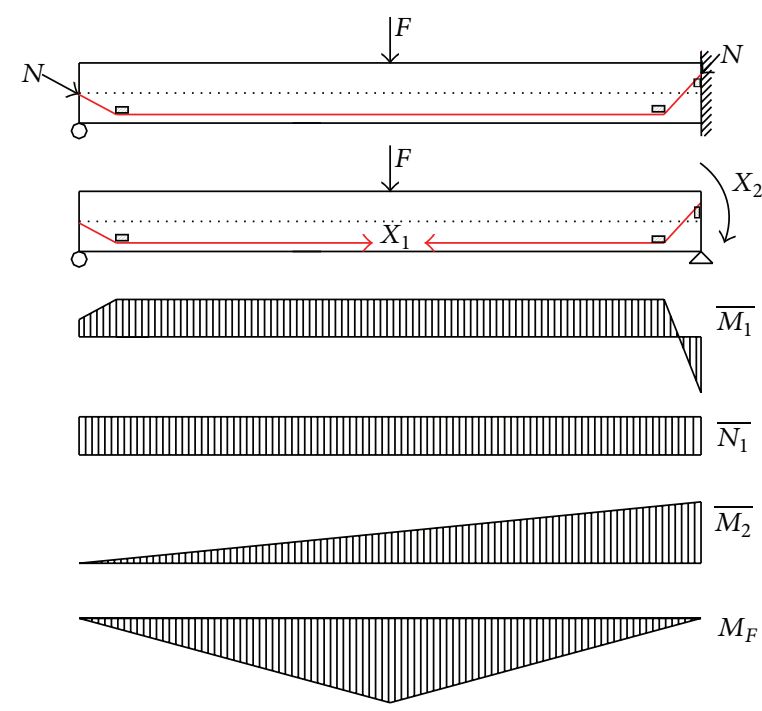

(a) The side span model
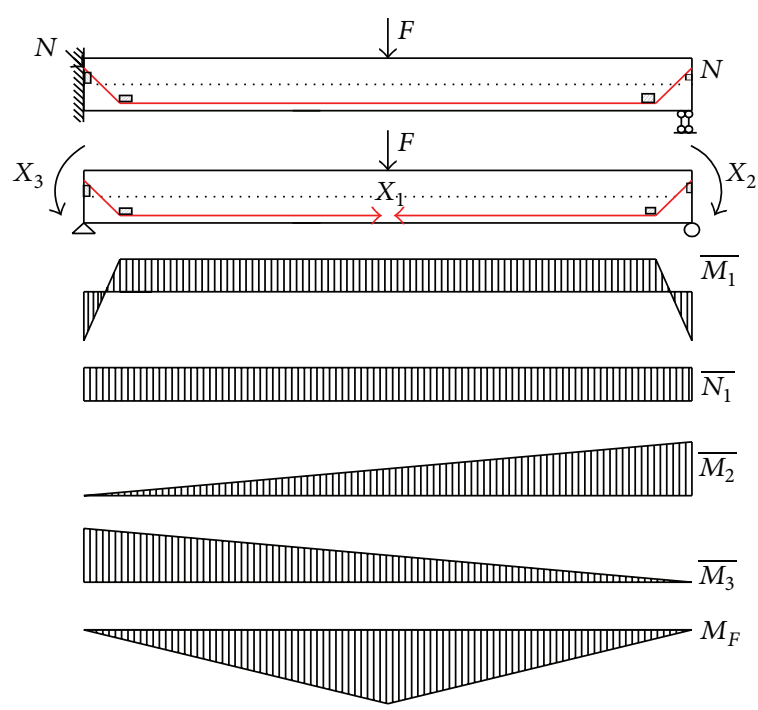

(b) The middle span model

FIgURE 3: The analysis model and bending moment diagram.

where

$$
\begin{aligned}
\phi= & (E I) \\
& \times\left(\frac{7\left(\delta_{11} \delta_{22}-\delta_{12} \delta_{21}\right) F L^{3}}{768\left(\delta_{12} \Delta_{2 F}-\delta_{22} \Delta_{1 F}\right)}-\frac{\left(\delta_{22} \Delta_{1 F}-\delta_{12} \Delta_{2 F}\right.}{\delta_{22} F}\right)^{-1} .
\end{aligned}
$$

The middle span $(2 \leqslant i \leqslant n-1)$ of the multispan externally prestressed concrete beam can be simplified as the structure which is shown in Figure 3(b). Concentrated force $F$ acts on the midspan of the middle span beam model and unknown forces are $X_{1}, X_{2}$, and $X_{3}$. The deformation compatibility equations can be expressed as follows:

$$
\begin{aligned}
& \delta_{11} X_{1}+\delta_{12} X_{2}+\delta_{13} X_{3}+\Delta_{1 F}=0 \\
& \delta_{21} X_{1}+\delta_{22} X_{2}+\delta_{23} X_{3}+\Delta_{2 F}=0 \\
& \delta_{31} X_{1}+\delta_{32} X_{2}+\delta_{33} X_{3}+\Delta_{3 F}=0
\end{aligned}
$$

where $\delta_{i j}$ and $\Delta_{i F}$ can be calculated by (5) and (13) can be rewritten as follows:

$$
\Delta N=\frac{D_{\Delta}}{D_{0}}
$$

where

$$
D_{\Delta}=\left|\begin{array}{lll}
\delta_{12} & \delta_{13} & \Delta_{1 F} \\
\delta_{22} & \delta_{23} & \Delta_{2 F} \\
\delta_{32} & \delta_{33} & \Delta_{3 F}
\end{array}\right|, \quad D_{0}=\left|\begin{array}{lll}
\delta_{11} & \delta_{12} & \delta_{13} \\
\delta_{21} & \delta_{22} & \delta_{23} \\
\delta_{31} & \delta_{32} & \delta_{33}
\end{array}\right| .
$$

The vertical displacement $\mu_{F}$ on the midspan of the middle span model can be expressed as follows:

$$
\mu_{F}=\frac{F L^{3}}{192 E I} .
$$

The vertical displacement $\mu_{\Delta N}$ caused by internal force can be written as follows:

$$
\mu_{\Delta N}=\frac{\left(\delta_{22}+\delta_{23}\right) \Delta_{1 F}-\left(\delta_{12}+\delta_{13}\right) \Delta_{2 F}}{\left(\delta_{22}+\delta_{23}\right) E I F} \Delta N .
$$

Substituting (16) and (17) into (10), the relationship between prestress variation $\Delta N$ and vibration displacement $u(x, t)$ can be expressed as in (11). But the coefficient $\phi$ can be written as follows:

$$
\begin{aligned}
\phi= & (E I) \\
& \times\left(\frac{F L^{3} D_{0}}{192 D_{\Delta}}-\frac{\left(\delta_{22}+\delta_{23}\right) \Delta_{1 F}-\left(\delta_{12}+\delta_{13}\right) \Delta_{2 F}}{\left(\delta_{22}+\delta_{23}\right) F}\right)^{-1} .
\end{aligned}
$$

2.4. Equivalent Eccentricity $H$. The equivalent eccentricity $H$ can be computed according to the principle which is that the areas of the bending moment diagram are equal $[10,14]$. As shown in Figure 3(b), the bending moment of the middle span caused by external tendons can be written as follows:

$$
\begin{aligned}
M_{N}=( & \overline{M_{1}}-\frac{\delta_{12} \delta_{22}-\delta_{13} \delta_{23}}{\delta_{22}^{2}-\delta_{23}^{2}} \overline{M_{2}} \\
& \left.-\frac{\delta_{13} \delta_{22}-\delta_{12} \delta_{23} \overline{M_{3}}}{\delta_{22}^{2}-\delta_{23}^{2}}\right) \Delta N .
\end{aligned}
$$

The area of the bending moment diagram is

$$
\begin{aligned}
S_{M_{N}}=( & S_{\overline{M_{1}}}-\frac{\delta_{12} \delta_{22}-\delta_{13} \delta_{23}}{\delta_{22}^{2}-\delta_{23}^{2}} S_{\overline{M_{2}}} \\
& \left.-\frac{\delta_{13} \delta_{22}-\delta_{12} \delta_{23}}{\delta_{22}^{2}-\delta_{23}^{2}} S_{\overline{M_{3}}}\right) \Delta N,
\end{aligned}
$$


where $S_{M_{N}}, S_{\overline{M_{1}}}, S_{\overline{M_{2}}}$, and $S_{\overline{M_{3}}}$ are the areas of the bending moment diagram which are shown in Figure 3(b). The equivalent eccentricity $H$ can be written as $H=S_{M N} /(\Delta N \times L)$, where $L$ is span length. Equation (20) can be written as follows:

$$
H=\frac{1}{L}\left(S_{\overline{M_{1}}}-\frac{\delta_{12} \delta_{22}-\delta_{13} \delta_{23}}{\delta_{22}^{2}-\delta_{23}^{2}} S_{\overline{M_{2}}}-\frac{\delta_{13} \delta_{22}-\delta_{12} \delta_{23}}{\delta_{22}^{2}-\delta_{23}^{2}} S_{\overline{M_{3}}}\right) .
$$

Similarly, the equivalent eccentricity $H$ of the side span can be written as follows:

$$
H=\frac{1}{L}\left(S_{\overline{M_{1}}}-\frac{\delta_{12}}{\delta_{22}} S_{\overline{M_{2}}}\right) .
$$

Substituting (11) into (2), we can get

$$
\begin{gathered}
E I \frac{\partial^{4} u_{i}(x, t)}{\partial x^{4}}+\left(N_{x i}-H_{i} \phi_{i}\right) \frac{\partial^{2} u_{i}(x, t)}{\partial x^{2}} \\
+m \frac{\partial^{2} u_{i}(x, t)}{\partial t^{2}}=0 .
\end{gathered}
$$

Equation (23) is the free vibration equation of the multispan externally prestressed concrete beam and the section rigidity and beam length can be modified as follows.

Kim et al. [8] considered that the total rigidity of prestressed beam $E I$ is the sum of the flexural stiffness of reinforced concrete beam $E_{c} I_{c}$ and the flexural stiffness of the prestressed steel $E_{s} I_{s}$ and took the prestressed steel as the cable which is fixed at both ends of the beam. According to the principle that the natural frequency of the cable is equal to that of the beam, we can obtain

$$
E_{s} I_{s}=N\left(\frac{L_{i}}{n \pi}\right)^{2} .
$$

The total rigidity of prestressed beam can be written as follows:

$$
E I=E_{c} I_{c}+N\left(\frac{L_{i}}{n \pi}\right)^{2}
$$

where $L_{i}$ is the beam length of the $i$ th span and $n$ is the modal order.

The prestress force on the cross section can be regarded as an axial force and a moment and the beam length will change under the axial force [15]. The actual beam length of the $i$ th span can be written as follows:

$$
L_{i}^{\prime}=\left(1-\frac{N_{x i}}{E A}\right) L_{i}
$$

where $L_{i}^{\prime}$ is the actual beam length of the $i$ th span. The section rigidity and beam length in (23) can be corrected according to (25) and (26) before solving it.

\section{Frequency Equation of Multispan Externally Prestressed Concrete Beam}

3.1. To Solve the Vibration Equation. Xiong et al. $[14,16]$ utilized Dirac function to establish vibration equation of externally prestressed continuous beam and this method is not suitable for the solution of the vibration equation of threespan and more than three-span externally prestressed continuous beam. This paper translates the vibration equation of the multispan externally prestressed concrete beam into vibration equations of multi-single-span beams which must satisfy the rotation angle and bending moment conditions. According to (23), the vibration equation of $i$ th single-span beam can be simplified as follows:

$$
\frac{\partial^{4} u_{i}(x, t)}{\partial x^{4}}+\frac{N_{x i}-H_{i} \phi_{i}}{E I} \frac{\partial^{2} u_{i}(x, t)}{\partial x^{2}}+\frac{m}{E I} \frac{\partial^{2} u_{i}(x, t)}{\partial t^{2}}=0 .
$$

For any mode of vibration, the lateral deflection $\mu_{i}(x, t)$ may be written in the form [17]

$$
u_{i}(x, t)=\phi_{i}(x) Y(t)
$$

where $\phi_{i}(x)$ is the modal deflection and $Y(t)$ is a harmonic function of time $t$. Then substitution of (28) into (27) yields

$$
\begin{gathered}
\phi_{i}^{\prime \prime \prime \prime}(x)+g^{2} \phi_{i}^{\prime \prime}(x)-a^{4} \phi_{i}(x)=0, \\
Y^{\prime \prime}(t)+\omega^{2} Y(t)=0,
\end{gathered}
$$

where $\omega^{2}=a^{4} E I / m, g_{i}^{2}=\left(N_{x i}-H_{i} \phi_{i}\right) E I$. Equation (29) is the fourth order constant coefficient differential equation and the assumption that the solution of (29) is $\Phi_{i}(x)=G e^{s x}$. Taking it into (29), we can get

$$
s_{1,2}= \pm i h_{i}, \quad s_{3,4}= \pm i n_{i},
$$

where $h_{i}=\sqrt{\left(a^{4}+\left(g_{i}^{4} / 4\right)\right)^{1 / 2}+\left(g_{i}{ }^{2} / 2\right)}, \quad n_{i}=$ $\sqrt{\left(a^{4}+\left(g_{i}{ }^{4} / 4\right)\right)^{1 / 2}-\left(g_{i}{ }^{2} / 2\right)}$.

The general solution of (29) can be written as follows:

$$
\begin{aligned}
\phi_{i}(x)= & A \sin \left(h_{i} x\right)+B \cos \left(h_{i} x\right) \\
& +C \sinh \left(n_{i} x\right)+D \cosh \left(n_{i} x\right),
\end{aligned}
$$

where $A, B, C$, and $D$ are constants which can be obtained by rotation angle and bending moment boundary conditions.

3.2. To Solve Modal Equation. As shown in Figure 2, the displacement and bending moment at the ends of the $i$ th single-span beam can be written as follows:

$$
\begin{aligned}
\phi(0) & =0, \quad \phi^{\prime \prime}(0)=-\frac{M_{i, i+1}}{E I} \\
\phi\left(L_{i}\right) & =0, \quad \phi^{\prime \prime}\left(L_{i}\right)=-\frac{M_{i+1, i}}{E I} .
\end{aligned}
$$


Using (32) and its second partial derivative, constants $A, B$, $C$, and $D$ can be obtained as follows:

$$
\begin{aligned}
& A=\frac{M_{i+1, i}-M_{i, i+1} \cos \left(h_{i} L_{i}\right)}{E I\left(h_{i}^{2}+n_{i}^{2}\right) \sin \left(h_{i} L_{i}\right)}, \\
& B=\frac{M_{i, i+1}}{E I\left(h_{i}^{2}+n_{i}^{2}\right)}, \\
& C=\frac{\cosh \left(n_{i} L_{i}\right) M_{i, i+1}-M_{i+1, i}}{E I\left(h_{i}^{2}+n_{i}^{2}\right) \sinh \left(n_{i} L_{i}\right)}, \\
& D=\frac{-M_{i, i+1}}{E I\left(h_{i}^{2}+n_{i}^{2}\right)} .
\end{aligned}
$$

Taking the values of constants into (32), model functions can be derived.

3.3. To Solve Frequency Equation. According to (32), the angle equation of the $i$ th single-span beam can be written as follows:

$$
\begin{aligned}
\theta_{i}(x)= & \eta_{i}\left[M_{i+1, i}-M_{i, i+1} \cos \left(h_{i} L_{i}\right)\right] \cos \left(h_{i} x\right) \\
& -\psi_{i}\left[M_{i+1, i}-\cosh \left(n_{i} L_{i}\right) M_{i, i+1}\right] \cosh \left(n_{i} x\right) \\
& -\eta_{i} M_{i, i+1} \sin \left(h_{i} L_{i}\right) \sin \left(h_{i} x\right) \\
& -\psi_{i} M_{i, i+1} \sinh \left(n_{i} L_{i}\right) \sinh \left(n_{i} x\right),
\end{aligned}
$$

where $\eta_{i}=h_{i} / E I\left(h_{i}^{2}+n_{i}^{2}\right) \sin \left(h_{i} L_{i}\right), \psi_{i}=n_{i} / E I\left(h_{i}^{2}+\right.$ $\left.n_{i}^{2}\right) \sinh \left(h_{i} L_{i}\right)$.

For the $i$ th support which is shown in Figure 2, the equation $M_{i}=M_{i, i+1}=M_{i, i-1}$ always stands up and the angles on both sides of the $i$ th support can be rewritten as follows:

$$
\begin{aligned}
\theta_{i, i+1}= & {\left[\psi_{i} \cosh \left(h_{i} L_{i}\right)-\eta_{i} \cos \left(h_{i} L_{i}\right)\right] M_{i} } \\
& -\left(\psi_{i}-\eta_{i}\right) M_{i+1}, \\
\theta_{i, i-1}= & \left(\psi_{i-1}-\eta_{i-1}\right) M_{i-1} \\
& -\left[\psi_{i-1} \cosh \left(n_{i-1} L_{i-1}\right)-\eta_{i-1} \cos \left(h_{i-1} L_{i-1}\right)\right] M_{i} .
\end{aligned}
$$

The angles on both sides of the $i$ th support must be equal $\left(\theta_{i, i-1}=\theta_{i, i+1}, 2 \leqslant i \leqslant n\right)$, so we can get

$$
X_{i-1} M_{i-1}+\left(Y_{i-1}+Y_{i}\right) M_{i}+X_{i} M_{i+1}=0,
$$

where $X_{i}=\psi_{i}-\eta_{i}, Y_{i}=\eta_{i} \cos \left(h_{i} L_{i}\right)-\psi_{i} \cosh \left(n_{i} L_{i}\right)$.

Equation (37) has $n+1$ unknowns and $n-1$ equations and taken (37) into matrix form

$$
\mathbf{\Omega M}=\mathbf{0},
$$

where $\mathbf{M}=\left[M_{1}, M_{2}, \ldots, M_{n+1}\right]^{T}$,

$$
\mathbf{\Omega}=\left[\begin{array}{cccccc}
X_{1} & Y_{1}+Y_{2} & X_{2} & & & 0 \\
& X_{2} & Y_{2}+Y_{3} & X_{3} & & \\
& & \cdots & \ldots & \ldots & \\
0 & & & X_{n-1} & Y_{n-1}+Y_{n} & X_{n}
\end{array}\right]
$$

The bending moment within the first and last span beam ends needs to satisfy that $M_{1}=0$ and $M_{n+1}=0$. Equation (38) can be simplified as follows:

$$
\Omega_{0} \mathbf{M}_{0}=\mathbf{0},
$$

where $\mathbf{M}_{\mathbf{0}}=\left[M_{2}, M_{3}, \ldots, M_{n}\right]^{T}$,

$$
\mathbf{\Omega}_{\mathbf{0}}=\left[\begin{array}{ccccc}
Y_{1}+Y_{2} & X_{2} & & & \\
X_{2} & Y_{2}+Y_{3} & X_{3} & & \\
& \cdots & \cdots & \ldots & \\
& & X_{n-2} & Y_{n-2}+Y_{n-1} & X_{n-1} \\
& & & X_{n-1} & Y_{n-1}+Y_{n}
\end{array}\right]
$$

Equation (40) must have a nonzero solution according to the physical meaning of the formula, so the frequency equation of the $n$ span externally prestressed concrete beam can be written as follows:

$$
\left|\begin{array}{ccccc}
Y_{1}+Y_{2} & X_{2} & & & \\
X_{2} & Y_{2}+Y_{3} & X_{3} & & \\
& \cdots & \cdots & \ldots & \\
& & X_{n-2} & Y_{n-2}+Y_{n-1} & X_{n-1} \\
& & & X_{n-1} & Y_{n-1}+Y_{n}
\end{array}\right|=0
$$

The initial $n$ roots can be obtained by calculating (42) which are the essential $n$ order frequencies of the $n$ span externally prestressed concrete beam.

\section{Method for Prestress Force Identification}

4.1. Identification from Frequency Equation and Measured Frequencies. In order to identify the prestress force according to the frequency equation (42), the frequency function $F(N)$ can be defined as follows:

$$
F(N)=\left|\begin{array}{ccccc}
Y_{1}+Y_{2} & X_{2} & & & \\
X_{2} & Y_{2}+Y_{3} & X_{3} & & \\
& \cdots & \cdots & \ldots & \\
& & X_{n-2} & Y_{n-2}+Y_{n-1} & X_{n-1} \\
& & & X_{n-1} & Y_{n-1}+Y_{n}
\end{array}\right|
$$

where $N$ is the prestress force which is the independent variable of the frequency function $F(N)$. Taking the measured frequency into the frequency function $F(N)$ and assuming that the frequency function is equal to zero $(F(N)=0)$, the prestress force can be obtained by solving the formula $F(N)=0$. The $i$ th order measured frequency $f_{i}$ is taken into frequency function $F(N)$. We can rewrite it as follows:

$$
F_{i}(N)=\left|\begin{array}{ccccc}
Y_{1}+Y_{2} & X_{2} & & & \\
X_{2} & Y_{2}+Y_{3} & X_{3} & & \\
& \cdots & \ldots & \ldots & \\
& & X_{n-2} & Y_{n-2}+Y_{n-1} & X_{n-1} \\
& & & X_{n-1} & Y_{n-1}+Y_{n}
\end{array}\right| .
$$


TABLE 1: Measured frequencies and identified prestress force of the single-span beam.

\begin{tabular}{lcccc}
\hline \multicolumn{2}{c}{ Measured frequency $(\mathrm{Hz})$} & \multicolumn{2}{c}{ Prestress force $(\mathrm{kN})$} \\
Mode 1 & Mode 2 & Test value & Identification value & Error $(\%)$ \\
\hline 37.549 & 138.049 & 0 & - & 32.70 \\
37.634 & 138.087 & 30.95 & 53.24 & 5.65 \\
37.703 & 138.123 & 51.31 & 96.22 & 3.76 \\
37.819 & 138.170 & 90.27 & 126.27 & 6.59 \\
37.912 & 138.215 & 120.36 & 4.91 \\
\hline
\end{tabular}

Note. Error denotes the (identified value - test value)/test value $\times 100 \%$, the same meaning in the Table 3 .

TABLE 2: The corrected result of material parameters and frequencies.

\begin{tabular}{|c|c|c|c|c|c|c|}
\hline & \multicolumn{2}{|c|}{ Material parameter } & \multicolumn{2}{|c|}{ Frequency result (HZ) of (42) } & \multicolumn{2}{|c|}{ Error $(\%)$} \\
\hline & Elastic modulus (Mpa) & Density $\left(\mathrm{kg} / \mathrm{m}^{3}\right)$ & Mode 1 & Mode 2 & Mode 1 & Mode 2 \\
\hline Uncorrected & $2.800 \times 10^{4}$ & 2500 & 38.347 & 143.998 & -2.12 & -4.31 \\
\hline Corrected & $2.851 \times 10^{4}$ & 2583 & 37.545 & 138.079 & 0.01 & -0.02 \\
\hline
\end{tabular}

Note. Error denotes the (mode with corrected or uncorrected material parameter - test mode)/test mode $\times 100 \%$, the same meaning in the Table 4 .

We can obtain $i$ frequency functions such as $F_{1}(N)$, $F_{2}(N), \ldots, F_{i}(N)$ if there are $i$ measured frequencies. The prestress force can be identified by looking for the zeros of the frequency functions if the measured frequencies are accurate enough. Actually, there are inevitable errors in the measured frequencies and the true prestress force will appear near the zero of the frequency function. If we still identified the prestress force at the zero of the frequency function, the errors of prestress force could be larger. In order to obtain more accurate results, the finite order measured frequencies are taken into the frequency function $F(N)$ and we can get the relationship equations about the true prestress force $N$ as follows:

$$
\begin{gathered}
F_{1}(N) \approx 0, \\
F_{2}(N) \approx 0, \\
F_{3}(N) \approx 0, \\
\vdots \\
F_{n}(N) \approx 0 .
\end{gathered}
$$

Graphs of (45) must have the intersection and the value of the independent variable at the intersection is the prestress force which needs to be identified. Concrete steps for the prestress force identification method will be given with examples in Section 4.

\section{Examples and Discussion}

5.1. Prestress Force Identification in a Single-Span Beam. A simply supported concrete beam with external tendons is studied. The length of the beam is $2.6 \mathrm{~m}$, and the height and the width of the section are $0.15 \mathrm{~m}$ and $0.12 \mathrm{~m}$, respectively. The concrete grade is $\mathrm{C} 35$, there is an external tendon $7 \varphi^{s} 5$
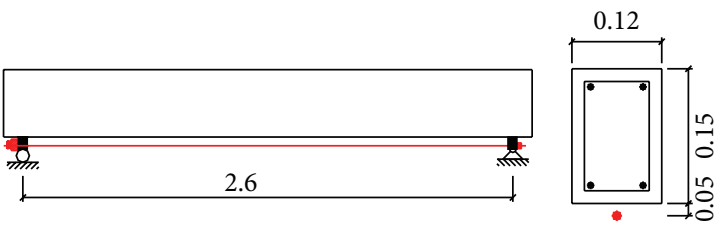

FIgURE 4: The single-span beam.

within the beam, the cross sectional area of the external tendon is $139 \mathrm{~mm}^{2}$, and eccentricity of the external tendon is $0.125 \mathrm{~m}$. Schematic diagram of the single-span concrete beam with external tendons is shown in Figure 4.

The biggest tensile force of the external tendon is $120 \mathrm{kN}$ according to principles that the tensile force cannot exceed $75 \%$ tensile strength and the eccentric compressive concrete beam cannot cause cracks under the prestress force. The stretching device is a hydraulic jack and pull-press sensor at the beam end. The tensile force in each tensioning stage is measured by the pull-press sensor. The external tendon was tensioned using multilevel tensioning method and the vibration signal of the beam using hammer to stimulate it was collected by the acceleration sensor at each tensioning stage. The photos of test are shown in Figure 5. When the test is completed, acceleration signals are analyzed by the methods of digital signal processing including FFT. The first two order frequencies of the single-span beam in each tensioning stage are obtained and shown in Table 1.

The values of material parameters such as elastic modulus and density cannot directly use the standard value because of the manufacturing error and material difference. The values of material parameters must be corrected before identifying the prestress force. On the basis of the external tendon layout completed and no tensioning, the values of material parameters are corrected by using the frequency equation (42) and the measured frequencies. After the completion of the correction, the first two order frequencies with the modified 
TABLE 3: Measured frequencies and identified prestress force of the two-span beam.

\begin{tabular}{|c|c|c|c|c|c|}
\hline \multicolumn{3}{|c|}{ Measured frequency $(\mathrm{Hz})$} & \multicolumn{3}{|c|}{ Prestress force $(\mathrm{kN})$} \\
\hline Mode 1 & Mode 2 & Mode 3 & Test value & Identification value & Error $(\%)$ \\
\hline 29.809 & 45.443 & 114.421 & 0 & - & - \\
\hline 30.141 & 46.062 & 116.129 & 71.52 & 75.31 & $5.30 \%$ \\
\hline 30.279 & 46.316 & 116.836 & 101.36 & 105.63 & $4.21 \%$ \\
\hline 30.466 & 46.659 & 117.790 & 139.71 & 149.27 & $6.84 \%$ \\
\hline 30.606 & 46.918 & 118.508 & 171.76 & 181.43 & $5.63 \%$ \\
\hline
\end{tabular}

material parameter by frequency equation (42) are fit with the measured frequencies which are shown in Table 2.

Obviously, the corrected results of the first two order frequencies have a good agreement with the measured frequencies at the external tendon layout completed and no tensioning stage.

The frequency function $F_{i}(N)$ of the simply supported concrete beam with external straight tendon according to (44) can be written as follows:

$$
\begin{aligned}
& F_{i}(N) \\
& =f_{i}-\frac{i E A}{2(E A-N) L} \sqrt{\frac{E I}{m}+\frac{N}{m}\left(\frac{L}{i \pi}\right)^{2}} \\
& \quad \times \sqrt{\left[\frac{i \pi E A}{(E A-N) L}\right]^{2}-\frac{N}{E I+N(L / i \pi)^{2}}+\frac{24 e^{2}}{L^{2}\left(e^{2}+4 r^{2}\right)}},
\end{aligned}
$$

where $f_{i}$ is the $i$ th frequency of the test beam, $e$ is the eccentricity of the external tendon, and $r$ is the radius of gyration. The frequency function $F_{i}(N)$ can be rewritten as $F_{1}(N)$ and $F_{2}(N)$ when $i=1$ and $i=2$ (to identify the prestress force using the 1st and 2 nd measured frequencies). The abscissa value of the intersection of the frequency functions $F_{1}(N)$ and $F_{2}(N)$ is the prestress force which needs to be identified. Graphs of frequency functions $F_{1}(N)$ and $F_{2}(N)$ are shown in Figure 6 and the identified prestress force and error are shown in Table 2.

Figure 6 shows that graphs of frequency functions $F_{1}(N)$ and $F_{2}(N)$ do meet in one point on every tensioning state and the intersection of the frequency functions $F_{1}(N)$ and $F_{2}(N)$ seems close to the function zero which match with theoretical analysis in Section 4.1. Table 2 shows that the identified prestress force is slightly larger than the true value and the maximum error is $6.59 \%$. This shows that the new method is available and can reflect the change trend of the prestress force in the beam.

5.2. Prestress Force Identification in a Two-Span Beam. A two-span concrete beam with external tendons is studied. The height of the beam is $0.36 \mathrm{~m}$, the width of the beam is $0.17 \mathrm{~m}$, concrete grade is $\mathrm{C} 20$, and the span length is $4.3 \mathrm{~m}+$ $4.3 \mathrm{~m}$. There is an external tendon $7 \varphi^{s} 5$ within the beam, the cross sectional area of the external tendon is $139 \mathrm{~mm}^{2}$, and the biggest tensile force of the external tendon is $180 \mathrm{kN}$. Test

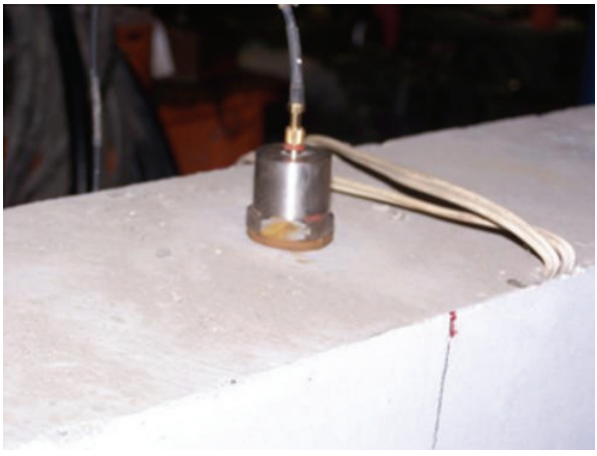

(a)

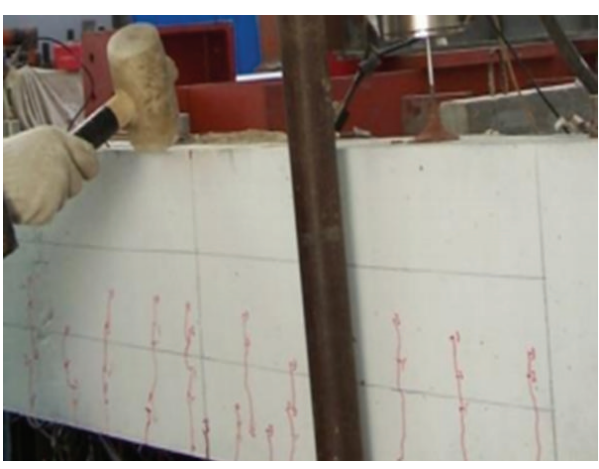

(b)

Figure 5: Photos of test.

method and procedure of the two-span beam are the same as the single-span beam. Schematic diagram of the two-span concrete beam with external tendons is shown in Figure 7. The first three order frequencies of the two-span beam in each tensioning stage are obtained and shown in Table 3.

Frequency equation of the two-span concrete beam with external tendons based on (38) can be obtained as follows:

$$
\sum_{i=1}^{2} \frac{h_{i} \cos \left(h_{i} L_{i}\right)}{\left(h_{i}^{2}+n_{i}^{2}\right) \sin \left(h_{i} L_{i}\right)}-\frac{n_{i} \cosh \left(n_{i} L_{i}\right)}{\left(h_{i}^{2}+n_{i}^{2}\right) \sinh \left(h_{i} L_{i}\right)}=0 \text {, }
$$

where (47) is not corrected by (25) and (26). The values of material parameters of the two-span concrete beam with external tendons must be corrected based on the first three order measured frequencies after (47) is corrected by (25) and (26) and the correction method is the same as the singlespan beam in Section 5.1. The corrected values of material parameters are shown in Table 4. 
TABLE 4: The corrected result of material parameters and frequencies.

\begin{tabular}{|c|c|c|c|c|c|c|c|c|}
\hline & \multicolumn{2}{|c|}{ Material parameter } & \multicolumn{3}{|c|}{ Frequency result (HZ) of (47) } & \multicolumn{3}{|c|}{ Error (\%) } \\
\hline & Elastic modulus (Mpa) & Density $\left(\mathrm{kg} / \mathrm{m}^{3}\right)$ & Mode 1 & Mode 2 & Mode 3 & Mode 1 & Mode 2 & Mode 3 \\
\hline Uncorrected & $2.550 \times 10$ & 2500 & 30.494 & 47.271 & 119.897 & 2.30 & 4.02 & 4.79 \\
\hline Corrected & $2.639 \times 10$ & 2591 & 29.832 & 45.527 & 114.797 & 0.08 & 0.18 & 0.33 \\
\hline
\end{tabular}
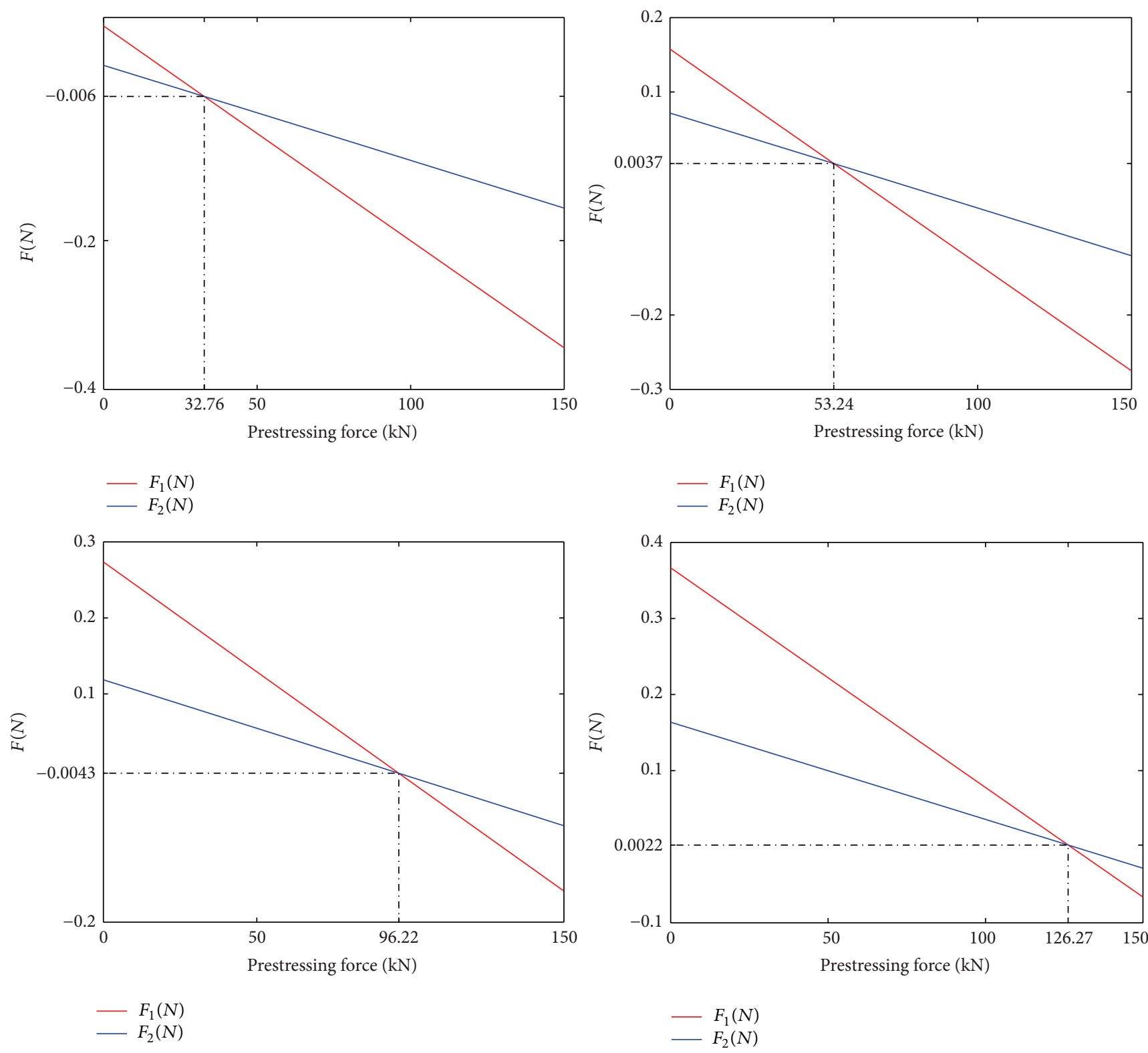

Figure 6: Graphs of frequency functions $F_{1}(N)$ and $F_{2}(N)$.
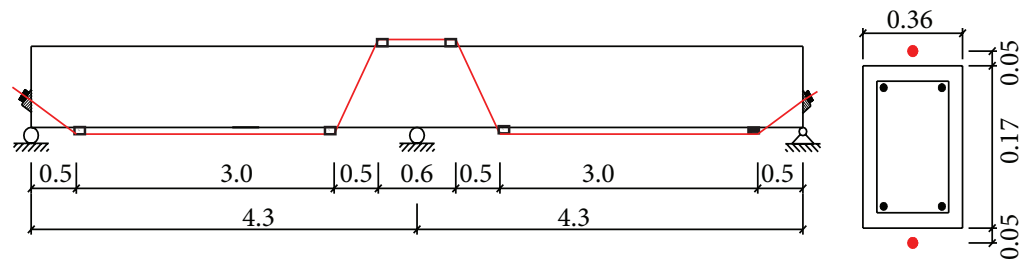

Figure 7: The two-span beam. 

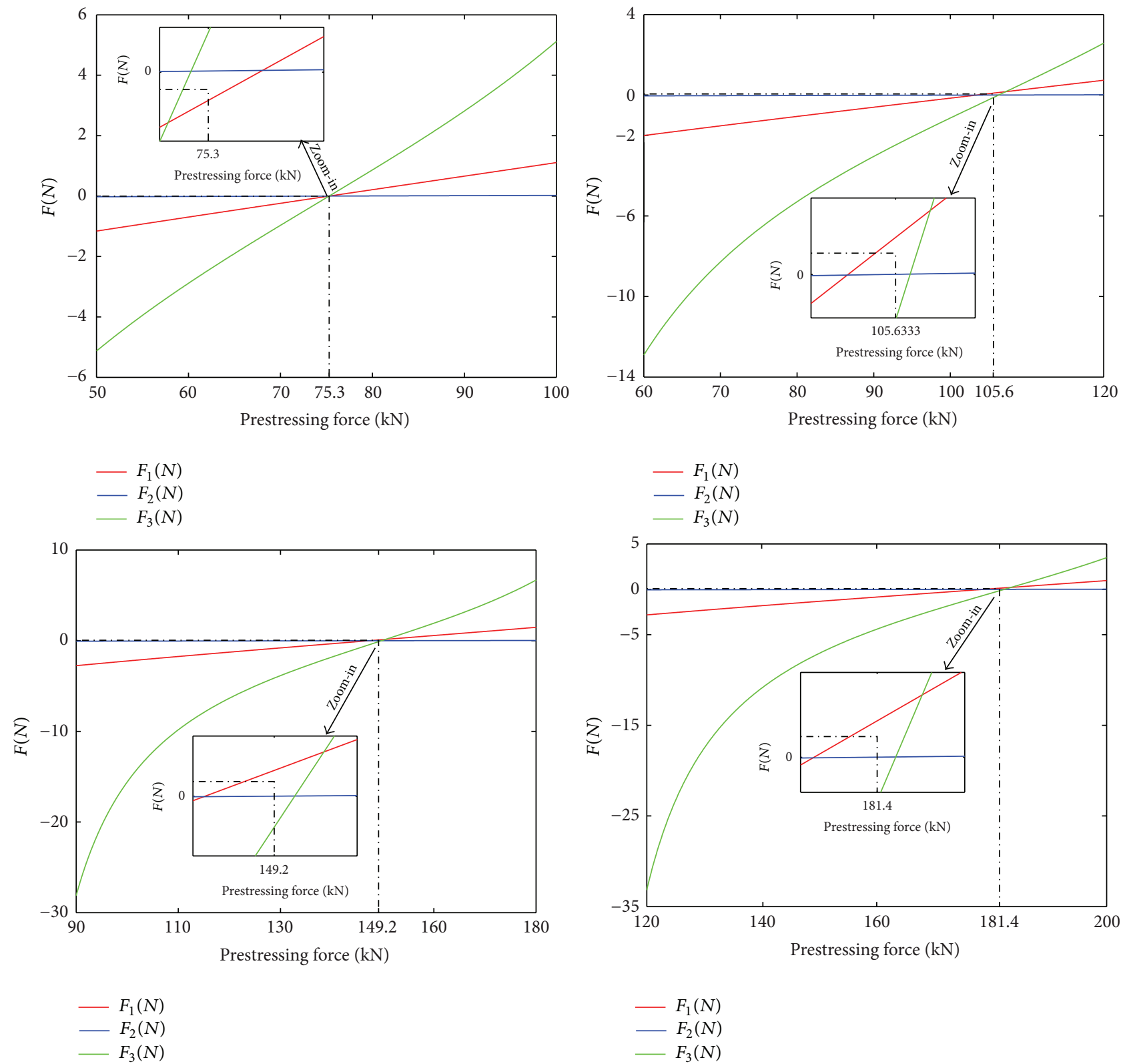

FIGURE 8: Graphs of frequency functions $F_{1}(N), F_{2}(N)$, and $F_{3}(N)$.

The frequency function $F_{i}(N)$ of two-span concrete beam with external tendons can be presented according to (44). The frequency function $F_{i}(N)$ can be rewritten as $F_{1}(N)$, $F_{2}(N)$, and $F_{3}(N)$ when $i=1, i=2$, and $i=3$ (to identify the prestress force using the first three measured frequencies). The abscissa value of the intersection of the frequency functions $F_{1}(N), F_{2}(N)$, and $F_{3}(N)$ is the identified prestress force. Because there are always errors with the measured frequencies, graphs of frequency functions $F_{1}(N)$, $F_{2}(N)$, and $F_{3}(N)$ cannot be accurate in one point. Actually, graphs of any two frequency functions can meet in one point and the three frequency functions will have three intersections. The prestress force of the two-span concrete beam will be identified based on the first three measured frequencies which will have higher accuracy than the result based upon the first two measured frequencies. The true prestress force will appear in the triangle with the three intersections. According to the geometric relationship of the triangle, the identified prestress force can be acquired by the abscissa value of the triangle of gravity. Graphs of frequency functions $F_{1}(N), F_{2}(N)$, and $F_{3}(N)$ are shown in Figure 8 and the identified prestress force and error are shown in Table 4.

Figure 8 shows that graphs of frequency functions $F_{1}(N)$, $F_{2}(N)$, and $F_{3}(N)$ have three intersections and frequency functions value at the triangle of gravity is closed to the functions zero which match with theoretical analysis above. 
TABLE 5: The error analysis results.

\begin{tabular}{|c|c|c|c|c|c|c|}
\hline \multicolumn{4}{|c|}{ Frequency error } & \multicolumn{3}{|c|}{ Prestress force $(\mathrm{kN})$} \\
\hline $\begin{array}{l}-3 \% \\
\text { Mode } 1 \\
\end{array}$ & $\begin{array}{c}3 \% \\
\text { Mode } 1 \\
\end{array}$ & $\begin{array}{c}-3 \% \\
\text { Mode } 2 \\
\end{array}$ & $\begin{array}{c}3 \% \\
\text { Mode } 2 \\
\end{array}$ & Theoretical value & Identification value & Error (\%) \\
\hline 0 & 0 & 1 & 0 & \multirow{8}{*}{60} & 65.15 & 8.58 \\
\hline 0 & 0 & 0 & 1 & & 54.85 & -8.58 \\
\hline 1 & 0 & 0 & 0 & & 58.59 & -2.35 \\
\hline 0 & 1 & 0 & 0 & & 61.43 & 2.38 \\
\hline 1 & 0 & 0 & 1 & & 53.44 & -10.93 \\
\hline 0 & 1 & 1 & 0 & & 66.59 & 10.98 \\
\hline 1 & 0 & 1 & 0 & & 63.75 & 6.25 \\
\hline 0 & 1 & 0 & 1 & & 56.29 & -6.18 \\
\hline 0 & 0 & 1 & 0 & \multirow{8}{*}{90} & 95.18 & 5.76 \\
\hline 0 & 0 & 0 & 1 & & 84.83 & -5.74 \\
\hline 1 & 0 & 0 & 0 & & 88.58 & -1.58 \\
\hline 0 & 1 & 0 & 0 & & 91.41 & 1.57 \\
\hline 1 & 0 & 0 & 1 & & 83.41 & -7.32 \\
\hline 0 & 1 & 1 & 0 & & 96.61 & 7.34 \\
\hline 1 & 0 & 1 & 0 & & 93.76 & 4.18 \\
\hline 0 & 1 & 0 & 1 & & 86.21 & -4.21 \\
\hline 0 & 0 & 1 & 0 & \multirow{8}{*}{120} & 125.2 & 4.33 \\
\hline 0 & 0 & 0 & 1 & & 114.31 & -4.74 \\
\hline 1 & 0 & 0 & 0 & & 118.57 & -1.19 \\
\hline 0 & 1 & 0 & 0 & & 121.43 & 1.19 \\
\hline 1 & 0 & 0 & 1 & & 113.38 & -5.52 \\
\hline 0 & 1 & 1 & 0 & & 126.67 & 5.56 \\
\hline 1 & 0 & 1 & 0 & & 123.77 & 3.14 \\
\hline 0 & 1 & 0 & 1 & & 116.63 & -2.81 \\
\hline
\end{tabular}

Note: "0" stands for the error which does not appear in the certain calculating condition and "1" stands for the error which appears in the certain calculating condition.

The identified prestress force appears near functions zero. Table 4 shows that the identified prestress force of the twospan concrete beam with external tendons is also larger than the true value and the maximum error is $6.89 \%$. Identification method for the prestress force based on the frequency equation and the measured frequencies can effectively identify the prestress force.

5.3. Effect of Measured Frequency Errors. Structural dynamic responses can be collected using the acceleration sensor in practical engineering and the natural frequencies can be obtained based on spectrum transformation with the acceleration data. The low order natural frequencies usually have higher precision than the high order natural frequencies. If test environment is relatively stable and the test beam does not show cracks and plastic deformation in the tensioning stage, the change of the measured frequencies reflects that the prestress force has effects on dynamic characteristics of the structure. The prestress force can be effectively recognized based on the measured frequencies and frequency functions of externally prestressed concrete beam which is presented in this paper. Natural frequencies which are obtained by the signal processing technology are relatively accurate, but there is a certain error between the measured results and the true values which is caused by the test method and data processing method. It is necessary to study that the identified result of the prestress force is affected by the error of the measured frequencies.

Taking the single-span beam which is shown in Section 5.1 as an example, the first two order frequencies under different prestress force $(N=60 \mathrm{kN}, 90 \mathrm{kN}$, and $120 \mathrm{kN}$ ) can be obtained by (42) and then assuming that the frequencies which are obtained by (42) have a maximum error of $\pm 3 \%$. The frequencies and the error can be combined to different calculating conditions. Frequencies with different errors in different calculating conditions are plugged into frequency functions (45). The graphs of frequency functions with the first two order frequencies will have the intersection and the identified prestress force can be modified with the intersection which is shown in Section 5. The error analysis results under different calculating conditions are shown in Table 5 .

Table 5 shows that the identified prestress force has a greater difference with the different frequency and the error combination in the same tensioning stage which illustrate that the error of natural frequency has significant effect on 
the accuracy of prestress force identification and the more accurate the measured frequencies are the higher precision the identified prestress force has. In different tensioning stage and the same frequency error, the smaller the prestress force is, the more significant effect by the frequency error the identified results have and the influence of frequency error for prestressed force identification will wane with the increase of tensioning force. The identified results are affected more significantly by the error of higher order frequency. Apparently, there exists nonlinear relationship between natural frequency and prestressed force. Above all, when the test environment is relatively stable and beam does not show cracks and plastic deformation in the tensioning stage, the natural frequencies are obtained more accurately using the right test method and data processing method; then the prestress force can be identified based on frequency equation and the measured frequencies and the identification accuracy for the prestress force depends on the accuracy of the measured frequencies. In the long-term bridge health monitoring, the dynamic response of the bridge can be collected by sensors, the influence of environmental factors and external incentives is eliminated in signals, and the measured frequencies are obtained by spectrum transformation. The prestress force of the bridge can be identified based on the frequency equation and the measured frequencies and the change trend of the prestress force can be reflected.

\section{Conclusion}

In this study, a new method to identify the prestress force in externally prestressed concrete beam based on the frequency equation and the measured frequencies is proposed. The effectiveness of the prestress force identification method is demonstrated by the single-span externally prestressed concrete beam and two-span externally prestressed concrete beam tests. Taking the single-span beam as an example, the influencing regularities of the error of the measured frequencies on the identified results are analyzed by numeric calculation. The free vibration equation of multispan externally prestressed concrete beam is solved using sublevel simultaneous method and the multispan externally prestressed concrete beam is taken as the multiple single-span beams which must meet the bending moment and rotation angle boundary conditions. The function relation between prestress variation and vibration displacement is built and the formula of equivalent eccentricity $H$ is presented. In the longterm bridge health monitoring, the measured frequencies can be obtained by practical signal processing. The prestress force of the bridge can be identified based on the new identified method and the change trend of the prestress force can be reflected.

\section{Conflict of Interests}

The authors declare that there is no conflict of interests regarding the publication of this paper.

\section{Acknowledgments}

This work is partially supported by Natural Science Foundation of China under Grant nos. 51378039 and 51108009 and Foundation of Beijing Lab of Earthquake Engineering and Structural Retrofit under Grant no. 2013TS02.

\section{References}

[1] American Association of State Highway Transportation Officials, Bridge Design Specifications, AASHTO, Washington, DC, USA, 4th edition, 2007.

[2] Z. R. Lu and S. S. Law, "Identification of prestress force from measured structural responses," Mechanical Systems and Signal Processing, vol. 20, no. 8, pp. 2186-2199, 2006.

[3] S. S. Law and Z. R. Lu, "Time domain responses of a prestressed beam and prestress identification," Journal of Sound and Vibration, vol. 288, no. 4-5, pp. 1011-1025, 2005.

[4] H. Li, Z. Lv, and J. Liu, "Assessment of prestress force in bridges using structural dynamic responses under moving vehicles," Mathematical Problems in Engineering, vol. 2013, Article ID 435939, 9 pages, 2013.

[5] S. S. Law, S. Q. Wu, and Z. Y. Shi, "Moving load and prestress identification using wavelet-based method," Journal of Applied Mechanics, Transactions ASME, vol. 75, no. 2, Article ID 021014, 7 pages, 2008.

[6] J. Q. Bu and H. Y. Wang, "Effective prestress identification for a simply-supported PRC beam bridge by BP neural network method," Journal of Vibration and Shock, vol. 30, no. 12, pp. 155159, 2011.

[7] M. A. Abraham, S. Park, and N. Stubbs, "Loss of prestress prediction based on nondestructive damage location algorithms," in Smart Structures and Materials, vol. 2446 of Proceedings of SPIE, pp. 60-67, March 1995.

[8] J.-T. Kim, Y.-S. Ryu, and C.-B. Yun, "Vibration-based method to detect prestress-loss in beam-type bridges," in Smart Systems and Nondestructive Evaluation for Civil Infrastructures, vol. 5057 of Proceedings of SPIE, pp. 559-568, March 2003.

[9] F. Z. Xuan, H. Tang, and S. T. Tu, "In situ monitoring on prestress losses in the reinforced structure with fiber-optic sensors," Measurement: Journal of the International Measurement Confederation, vol. 42, no. 1, pp. 107-111, 2009.

[10] A. Miyamoto, K. Tei, H. Nakamura, and J. W. Bull, "Behavior of prestressed beam strengthened with external tendons," Journal of Structural Engineering, vol. 126, no. 9, pp. 1033-1044, 2000.

[11] E. Hamed and Y. Frostig, "Natural frequencies of bonded and unbonded prestressed beams-prestress force effects," Journal of Sound and Vibration, vol. 295, no. 1-2, pp. 28-39, 2006.

[12] M. Saiidi, B. Douglas, and S. Feng, "Prestress force effect on vibration frequency of concrete bridges," Journal of Structural Engineering, vol. 120, no. 7, pp. 2233-2241, 1994.

[13] M. Saiidi, B. Douglas, and S. Feng, "Prestress force effect on vibration frequency of concrete bridges," Journal of Structural Engineering, vol. 122, no. 4, p. 460, 1996.

[14] X. Y. Xiong, F. Gao, and Y. Li, "Analysis on vibration behavior of externally prestressed concrete continuous beam," Journal of Vibration and Shock, vol. 30, no. 6, pp. 105-109, 2011.

[15] S. Timoshenko, Strength of Materials, D. Van Nostrand Company, Inc, New York, NY, USA, 1940. 
[16] R. J. Hosking, S. A. Husain, and F. Milinazzo, "Natural flexural vibrations of a continuous beam on discrete elastic supports," Journal of Sound and Vibration, vol. 272, no. 1-2, pp. 169-185, 2004.

[17] R. W. Clough and J. Penzien, Dynamics of Structure, Computers and Structures, Inc, New York, NY, USA. 


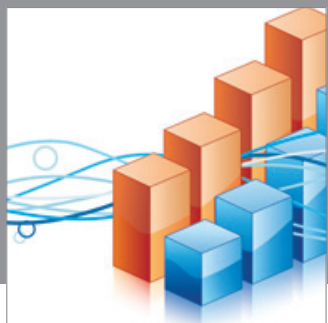

Advances in

Operations Research

mansans

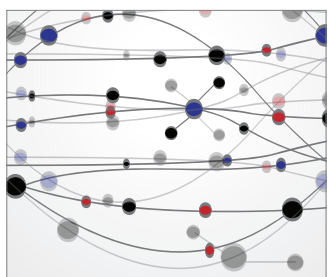

The Scientific World Journal
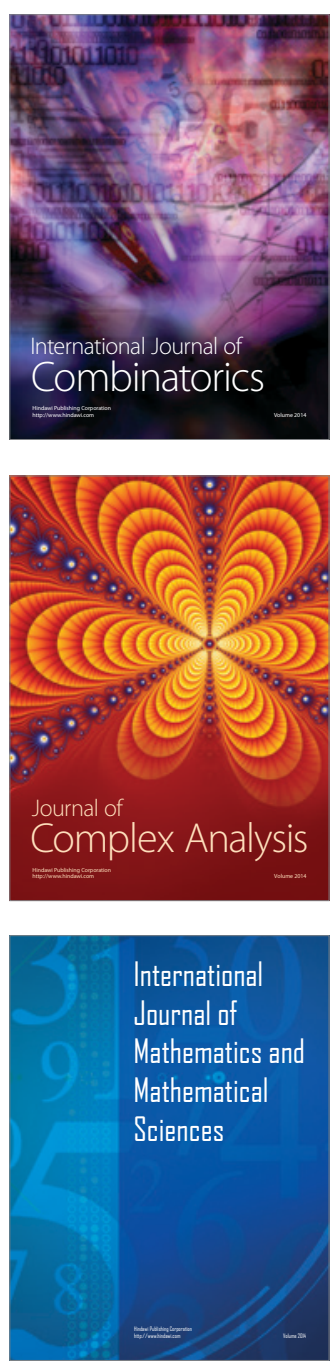
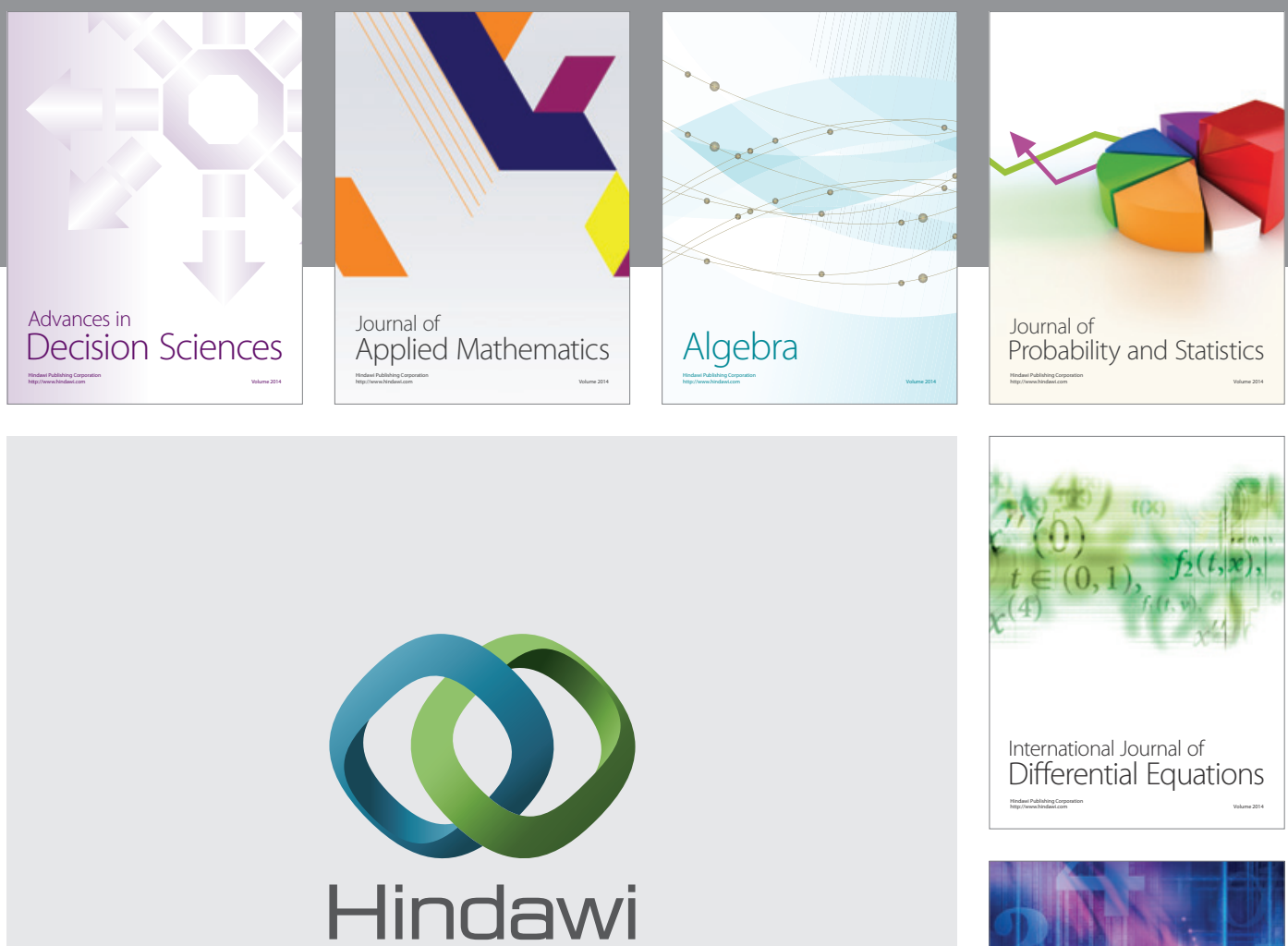

Submit your manuscripts at http://www.hindawi.com
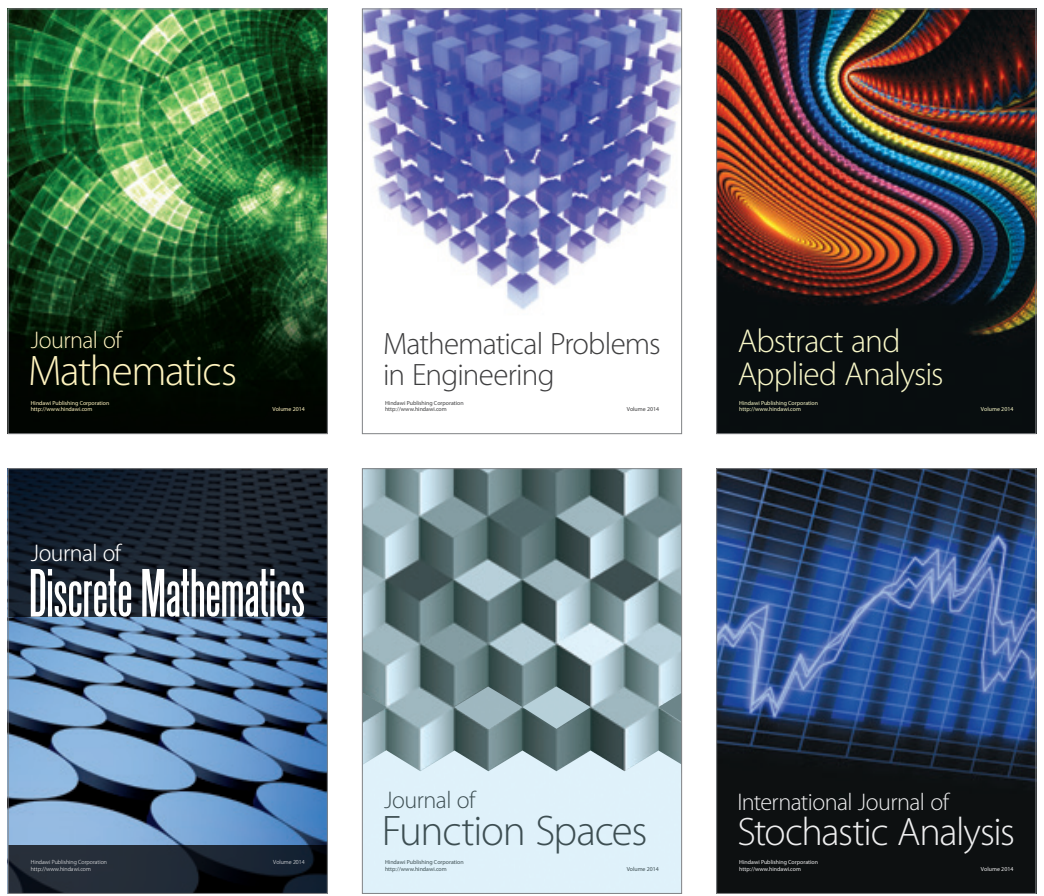

Journal of

Function Spaces

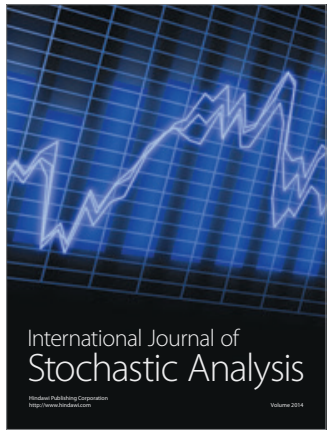

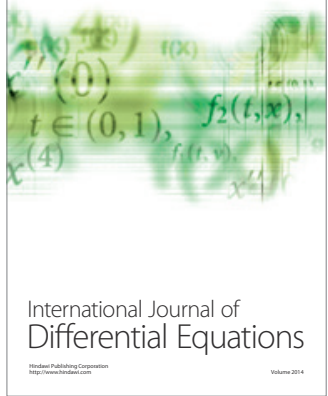
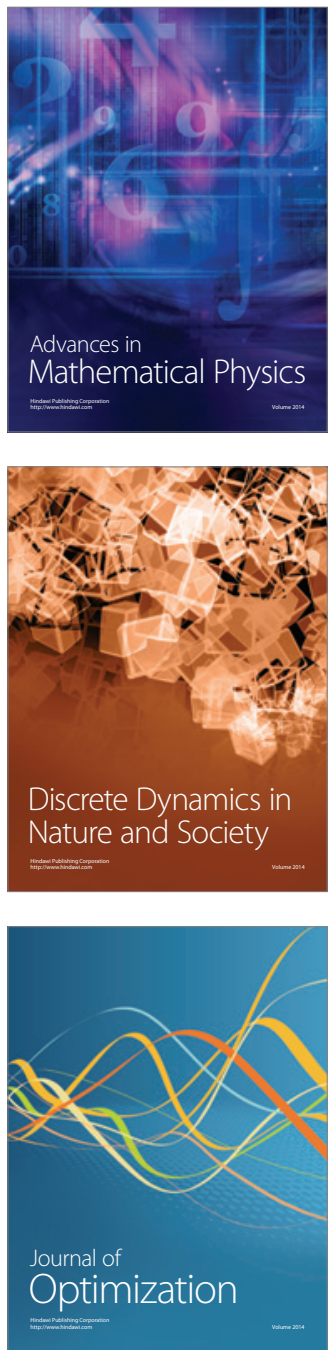